\title{
Root Distribution Patterns of Nine Apple Rootstock in Two Contrasting Soil Types
}

\author{
R. Thomas Fernandez'and Ronald L. Perry ${ }^{2}$ \\ Department of Horticulture, Michigan State University, East Lansing, MI 48824-1325 \\ David C. Ferree ${ }^{2}$ \\ Department of Horticulture, Ohio Agricultural Research and Development Center, The Ohio State \\ University, Wooster, OH 44691-4096
}

\begin{abstract}
Additional index words. Malus domestics, root distribution, soil bulk density
Abstract. Root distribution of 'Starkspur Supreme Delicious' on nine apple (Malus domestics Borkh.) rootstock grown in two different soil types in the 1980 NC-140 Uniform Apple Regional Rootstock Trial (Michigan and Ohio sites) was determined using the trench profile method. Based on the number of roots counted per tree, rootstock could be separated into five groups for the Marlette soil from most to least: MAC.24 > OAR1 > M.26EMLA = M.9EMLA > M.7EMLA = 0.3 $=$ M.9 = MAC.9 $>$ M.27EMLA. For the Canfield soil, rootstock were ranked for number of roots counted from most to least as follows: MAC.24 > OAR 1. MAC.9 = M.7EMLA > M.26EMLA = 0.3 = M.9 EMLA = M.9. Root distribution pattern by depth was affected by soil type with roots fairly well distributed throughout the Marlette soil but restricted primarily above the fragipan in the Canfield soil. Two rootstock performed differently from others in adapting to soil conditions at the different sites. MAC.9 had the second lowest number of total roots/dm in the Marlette soil yet the second most in the Canfield soil, while the opposite was found for M.9EMLA. Regression analysis demonstrated positive correlations between number of roots counted and vigor and yield of the scion.
\end{abstract}

The NC- 140 Technical Committee was established in 1967 with the central objective of facilitating cooperative research on new rootstock and their adaptability to environmental conditions of different North America regions (Ferree and Perry, 1988). Cooperators agreed to follow the Technical Committee's planting design and cultural guidelines for tree training and support, thinning, and fertilizing as well as to collect specific data. Cooperators were encouraged to collect additional data on specific interests such as those reported in this study. The 1980 NC-140 Uniform Apple Regional Rootstock Trial consisted of 'Starkspur Supreme Delicious' (Malus domestics Borkh.) on nine rootstock of varying size. Rootstock vigor listed from least to most dwarfing for the Michigan and Ohio plantings were as follows: MAC.24, M.7 EMLA, OAR1, M.26EMLA, Ottawa 3 (0.3), M.9EMLA, M.9, MAC.9, and M.27EMLA with OAR1 being more dwarfing than M.26EMLA and M.9 more dwarfing than MAC9 in Ohio (NC140, 1991).

Physical characteristics of soil have been found to influence root growth and distribution patterns (Cockroft and Wallbrink, 1966; Oskamp, 1932; Rogers and Vyvyan, 1934; Taylor and Gardner, 1963). Root systems may be confined to areas above hardpans with high soil bulk densities due to the inability of roots to penetrate them (Eavis and Payne, 1968, Greaten et al., 1968). Knowledge of root distribution patterns under various soil conditions is important to aid in rootstock selection. Trees with root systems capable of penetrating fragipans or adapting to other adverse soil condition, need to be identified for use in such situations. The ability of root systems to adapt to soil environments

Received for publication 13 Dec. 1993. Accepted for publication 22 June 1994, Acknowledgement is made to the Michigan Agricultural Experiment Station, the Ohio Agricultural Experiment Station, and the Michigan Apple Research Committee for their support of this research. The authors also wish to thank Daniel Kort, Kenneth Gordon, Mark Longstroth, Joan Runkel, and John Schmid for their assistance with this project. The cost of publishing this paper was defrayed in part by the payment of page charges. Under postal regulations, this paper therefore must be hereby marked advertisement solely to indicate this fact.

'Research associate.

${ }^{2}$ Professor. is important when selecting rootstock for orchards and experimental plots. Preliminary data on the overall rooting intensity and percent distribution of root size categories was requested for inclusion in volume 45 of Fruit Varieties Journal, which contained summary reports of this NC-140 rootstock trial (Fernandez et al., 1991 ). This paper will report on root distribution patterns, soil characteristics of the sites and relationships between rooting intensity, and scion vigor and yield. The objectives of this study were to describe the root distribution pattern of nine clonal apple rootstock at two NC-140 trial locations with highly different soil characteristics, determine root adaptation to soil environment, including soil type and soil impedance, and determine the relationship of scion growth and yield parameters to root system characteristics.

\section{Materials and Methods}

The 1980 NC- 140 Uniform Apple Regional Rootstock Trial consisted of 'Starkspur Supreme Delicious' propagated on nine rootstock. Sites located at Michigan State Univ., East Lansing and Ohio State Univ., Ohio Agricultural Research and Development Center, $\mathrm{OH}$ were used for this study based on the contrasting soil types and conditions. Trees were planted with a $3.5 \mathrm{~m}$ within-row and $5.5 \mathrm{~m}$ between-row spacing with north to south row orientation and $1 \mathrm{~m}$ wide herbicide strip in a randomized complete block with five single tree replicates. Trees were trained to a central leader without support and received similar management practices at both sites.

The soil series in Michigan was a Marlette fine sandy loam (Fine-loamy, mixed, mesic Glossoboric Hapludalfs) moderately well drained with moderate to moderately slow permeability (Anonymous, 1979). The soil series in Ohio was a Canfield silt loam (Fine-loamy, mixed, mesic Aquic Fragiudalfs) with a fragipan 60 to $70 \mathrm{~cm}$ below the soil surface with moderate permeability characterizing the soil above the fragipan and poor permeability through the fragipan (Anonymous, 1981). Soil bulk densities for each location were determined by sampling intact soil cores of a known volume in the trenches dug for counting roots. Soil core 
volumes were 350 and $230 \mathrm{~cm}^{3}$ for the samples from the Marlette and Canfield soils. Ten soil cores were taken for each soil horizon (six for Marlette and five for Canfield) within the $1.2 \mathrm{~m}$ from the soil surface that corresponded to the vertical height of the root counting frames described below. Each horizon was assumed to have the same bulk density throughout based on field observation and characteristics reported in the soil surveys (Anonymous, 1979, 198 1). Specific information on soil characteristics can be found in the soil surveys.

Roots were counted using the profile wall method because of the ability to investigate root distribution with soil profile characteristics (Layne et al., 1986; Oskamp and Batjer, 1932; Perry et al., 1983). Excavation began 9 Oct. 1989 in Ohio and 30 Apr. 1990 in Michigan. Since the highest proportion of roots are found within $1 \mathrm{~m}$ from the center of the trunk of apple trees (Atkinson, 1980), trenches were excavated with a backhoe parallel to tree rows within the herbicide strip $0.8 \mathrm{~m}$ from the center of the trunks on east and west sides of the tree. The most common range for depth of rooting of apple is from 1 to $2 \mathrm{~m}$ (Atkinson, 1980), therefore, the trenches were 1.5 to $2 \mathrm{~m}$ deep. Root counting frames were constructed $1.2 \mathrm{~m}$ vertical height $\mathrm{x} 1.8 \mathrm{~m}$ wide and divided with cotton string into mapping grid squares of $15 \mathrm{~cm}$ vertical height $\mathrm{x}$ $30 \mathrm{~cm}$ wide. The soil on the face of the trench was loosened an additional $5 \mathrm{~cm}$ deep perpendicular to the soil profile and washed with a high pressure water gun to expose roots. Counting frames were placed over the washed profiles with the top level with the soil surface and centered on the trunks. Roots were counted and sized on corresponding paper grids as described by Layne et al. (1986) to a depth of $1.2 \mathrm{~m}$ from the soil surface and $0.9 \mathrm{~m}$ to the north or south of the center of the tree trunk. Roots were counted for all surviving replicates of each rootstock (five for MAC.24, OAR 1, M.9 EMLA, M.7 EMLA, MAC.9, M.27 EMLA and four for M.26 EMLA, O.3 and M.9 on the Marlette soil; five for MAC.24, OAR 1, M.26 EMLA, MAC.9; four for M.7 EMLA, O.3, M.9; and two for M.9 EMLA on the Canfield soil). Roots were classified into total roots and three size categories: less than $2 \mathrm{~mm}$ (small), 2 to 5 $\mathrm{mm}$ (medium), and greater than $5 \mathrm{~mm}$ in diameter (large) and expressed per $\mathrm{dm}^{2}$ trench wall surface area. Tree height, canopy spread, trunk cross-sectional area (TCA), yield and yield efficiency were recorded as required by the NC-140 technical committee (NC-140, 1991).

Analysis of variance was conducted using the PROC GLM procedure of the SAS statistical program (SAS Institute, Cary, N.C.). Data from each location were analyzed separately as randomized complete blocks. The analysis of variance for the root mapping indicated little to no effect on root numbers due to the east or west facing profile of the tree or due to distance north or south in the row from the center of the trunk (data not shown), therefore, both profiles and all distances were combined for analysis for each tree. Data were analyzed to determine the relationship between number and size of roots at each depth by rootstock and presented as numbers of roots $/ \mathrm{dm}^{2}$ trench wall surface area. Differences in number of roots $/ \mathrm{dm}^{2}$ by depth also were analyzed for each rootstock.

Linear regression analysis for each location was conducted using the PROC REG procedure of the SAS statistical program to determine the relationships between the number of roots counted vs. vigor and yield components. Total number of small, medium and large roots were regressed against TCA, tree height, canopy spread, and yield data from 1989 and 10 year cumulative yield. Regression analysis also was performed for the above comparisons for number of medium and large roots combined, since the relationships with medium or large roots alone were found to have the highest coefficients of determination $\left(R^{2}\right)$. Discussion of linear regression will be concerned with models involving total roots and those having the highest $R^{2} \mathrm{~s}$.

\section{Results and Discussion}

Soil bulk densities were higher for cores taken at an average depth of 59-to 64-cm and 103-to 108-cm compared to cores from 17 to $22 \mathrm{~cm}$ and 33 to $38 \mathrm{~cm}$ for the Marlette soil with no other differences found (Table 1). Soil cores taken at an average depth range of 40 to 47,51 to 58 and 66 to $73 \mathrm{~cm}$ had higher bulk densities than the cores taken at 12 to $19 \mathrm{~cm}$ for the Canfield soil (Table 1 ). In addition, soil cores taken at 51 to $58 \mathrm{~cm}$ had higher bulk densities than those taken at 26 to $33 \mathrm{~cm}$ for this soil. The bulk densities recorded for soil cores taken at the 66 to $73 \mathrm{~cm}$ depth range, the location of the beginning of the fragipan, were much higher than all other soil core depths for the Canfield soil. Although the highest bulk densities were similar for the Marlette and Canfield soils, the highest bulk density for the Canfield soil was reached at an average depth range of 66 to $73 \mathrm{~cm}$ while the Marlette soil showed one area of high bulk density at a depth range of 103 to $108 \mathrm{~cm}$.

The nine rootstock were ranked for rooting intensity (number of roots per trench wall surface area) based on the total number of roots/ $\mathrm{dm}^{2}$ overall depths (Table 2) for the Marlette soil as follows: MAC.24 > OAR1 > M.26EMLA $=$ M.9EMLA > M.7EMLA $=0.3$ = M.9 = MAC.9 > M.27EMLA. For the Marlette soil, rooting intensity regardless of root size category generally followed the same order as for tree vigor except M.7EMLA which was ranked lower and M.9EMLA which was ranked higher in total number of roots/ $\mathrm{dm}^{2}$ than their tree vigor ranking.

Rootstock were ranked according to rooting intensity based on the total number of roots $/ \mathrm{dm}^{2}$ over all depths (Table 2) for the Canfield soil as follows: MAC.24>OAR $1=$ MAC.9 = M.7EMLA $>$ M.26EMLA $=0.3=$ M.9 EMLA $=$ M.9. Trees on M.27EMLA were not included in the root mapping of the Ohio site since all but one replicate died before excavation due to severe winter frost heaving that exposed the root system and resulted in root injury and

Table 1. Depth and bulk density of soil horizons of the Marlette and Canfield soils. Soil core volume was 350 and $230 \mathrm{~cm}^{3}$ in the Marlette and Canfield soils, respectively. Depth to the top and bottom of the soil core was measured from the soil surface.

\begin{tabular}{lccc}
\hline \hline Soil & $\begin{array}{c}\text { Depth of } \\
\text { horizon } \\
\text { horizon }\end{array}$ & $\begin{array}{c}\text { Depth from top to } \\
\text { bottom of core } \\
\text { sample }(\mathrm{cm})\end{array}$ & $\begin{array}{c}\text { Bulk density of core } \\
\text { sample }\left(\mathrm{g} \cdot \mathrm{cm}^{-3}\right)\end{array}$ \\
\hline & \multicolumn{3}{c}{ Marlette soil } \\
Ap & $0-28$ & $17-22$ & 1.38 \\
B\&A & $36-51$ & $33-38$ & 1.40 \\
B21t & $51-67$ & $59-64$ & 1.55 \\
B22t & $67-86$ & $82-87$ & 1.50 \\
c 1 & $86-106$ & $103-108$ & 1.58 \\
C2 & $106-153$ & $127-132$ & 1.50 \\
LSD & & & 0.14 \\
& & Canfield soil & 1.40 \\
Ap & $0-20$ & $12-19$ & 1.41 \\
2Btl & $30-53$ & $26-33$ & 1.46 \\
2Btl & $30-53$ & $40-47$ & 1.48 \\
2Bt2 & $53-65$ & $51-58$ & 1.61 \\
2Btx 1 & $65-100$ & $66-73$ & 0.06 \\
LSD & & & $1981)$ \\
\hline Depth & & & \\
\hline
\end{tabular}

${ }^{\bar{z}}$ Depth of soil horizons as reported in Anonymous (1979, 1981). ${ }^{y} \mathrm{LSD}$ at $P=0.05$. 
Table 2. Average number of roots $/ \mathrm{dm}^{2}$ over all depths for total roots and each size category for the Marlette and Canfield soils.

\begin{tabular}{|c|c|c|c|c|c|c|c|c|}
\hline \multirow[b]{2}{*}{ Rootstock } & \multicolumn{4}{|c|}{ Marlette soil } & \multicolumn{4}{|c|}{ Canfield soil } \\
\hline & Total & Small & Medium & $\overline{\text { Large }}$ & Total & Small & Medium & $\overline{\text { Large }}$ \\
\hline \multicolumn{9}{|c|}{ Roots/dm ${ }^{2}$} \\
\hline MAC. 24 & 5.01 & 4.75 & 0.15 & 0.11 & 4.36 & 3.89 & 0.29 & 0.18 \\
\hline OAR 1 & 3.65 & 3.38 & 0.19 & 0.08 & 2.86 & 2.56 & 0.21 & 0.09 \\
\hline M.26 EMLA & 3.07 & 2.93 & 0.10 & 0.04 & 2.13 & 2.02 & 0.07 & 0.04 \\
\hline M.9 EMLA & 2.81 & 2.69 & 0.08 & 0.04 & 1.64 & 1.49 & 0.10 & 0.05 \\
\hline M.7 EMLA & 2.17 & 2.04 & 0.08 & 0.05 & 2.41 & 2.18 & 0.14 & 0.09 \\
\hline 0.3 & 2.02 & 1.91 & 0.08 & 0.03 & 2.07 & 1.86 & 0.12 & 0.09 \\
\hline M.9 & 1.88 & 1.79 & 0.06 & 0.03 & 1.62 & 1.50 & 0.08 & 0.04 \\
\hline MAC.9 & 1.76 & 1.68 & 0.07 & 0.01 & 2.73 & 2.58 & 0.11 & 0.04 \\
\hline M.27 EMLA & 1.48 & 1.42 & 0.05 & 0.01 & --- & & --- & --- \\
\hline $\mathbf{L S D}^{\mathrm{z}}$ & 0.30 & 0.29 & 0.02 & 0.02 & 0.55 & 0.50 & 0.05 & 0.03 \\
\hline
\end{tabular}

'sso at $P=0.05$ comparing rootstock for each size category.

subsequent death (Warmund et al., 1991). As in the Marlette soil, rooting intensity for all mot size categories followed the same ranking as for tree vigor except MAC.9 was ranked higher than expected for rooting intensity when compared to tree vigor ranking.

Root distribution throughout the soil profiled showed different patterns for rootstock and soil types (Figs. 1 and 2). For the Marlette soil, total and small roots/dm² were fairly evenly distributed by depth (Fig. 1 A and B) with a moderate decrease in roots/ $\mathrm{dm}^{2}$ at the lowest depths with the exception of M.26EMLA, which showed an increase for the lowest depths. Most rootstock, except MAC.24, MAC.9 and M.26EMLA, showed a slight increase in number of total and small roots $/ \mathrm{dm}^{2}$ at the 15 to $30 \mathrm{~cm}$ depth compared to the 0 to $15 \mathrm{~cm}$ depth. Medium roots $/ \mathrm{dm}^{2}$ showed a large decrease in number from the 30 to $45 \mathrm{~cm}$ depth and below and large roots $/ \mathrm{dm}^{2}$ from the 15 to $30 \mathrm{~cm}$ depth and below (Fig. $1 \mathrm{C}$ and D). Only the most vigorous rootstock, MAC.24, OAR1 and M.26EMLA, had an average number of large roots $/ \mathrm{dm}^{2}$ below the 15 to $30 \mathrm{~cm}$ depth that was significantly greater than zero.

The root distribution pattern for total roots $/ \mathrm{dm}^{2}$ in the Canfield soil was much more consistent across rootstock (Fig.2). All rootstock showed a gradual decrease in number of total roots $/ \mathrm{dm}^{2}$ from the $\mathrm{O}$ to $15 \mathrm{~cm}$ depth to the 45 to $60 \mathrm{~cm}$ depth with a considerable decrease subsequently (Fig. 2A). There was up to an order of magnitude difference in roots in the depths above the 60 to $75 \mathrm{~cm}$ range compared to the depths from 60 to $75 \mathrm{~cm}$ and below. The depths from 60 to $75 \mathrm{~cm}$ and below roughly correspond with the location of the fragipan in the Canfield soil (Anonymous, 198 1; Table 1). The same root distribution pattern was seen for small, medium and large roots $/ \mathrm{dm}^{2}$ as for total roots $/ \mathrm{dm}^{2}$ except for each larger root size category roots were restricted to shallower portions of the profile (Fig. $2 \mathrm{~B}$ and D). For small roots $/ \mathrm{dm}^{2}$ the pattern was identical to total roots $/ \mathrm{dm}^{2}$ with a large decrease from 60 to $75 \mathrm{~cm}$ and below (Fig. 2B), for medium roots $/ \mathrm{dm}^{2}$ there were virtually no roots from 45 to $60 \mathrm{~cm}$ depth and below, for most rootstock (Fig. 2C) For large roots $/ \mathrm{dm}^{2}$ almost no roots were found from the 15 to $30 \mathrm{~cm}$ depth and below in most instances (Fig. 2D). MAC.24 typically maintained a higher number of roots $/ \mathrm{dm}^{2}$ to a greater depth than the other rootstock while M.26EMLA, M.9EMLA, M.9 and MAC.9 usually had very sparse rooting below $45 \mathrm{~cm}$, with the others intermediate.

Although statistical comparison between the two soil types cannot be conducted, the difference in ranking of the rooting intensity of the rootstock can be used to estimate relative performance at the two locations, MAC.9 and M.9EMLA switched ranking for the two soil types. MAC.9 had the second lowest number of roots $/ \mathrm{dm}^{2}$ per tree in the Marlette soil, ahead of M.27EMLA only, yet the second highest in the Canfield soil, similar to OAR 1 (Table 2). M.9EMLA was in the third highest grouping of number of roots $/ \mathrm{dm}^{2}$ per tree behind OAR1 in the Marlette soil but had the fewest roots $/ \mathrm{dm}^{2}$ per tree in the Canfield soil. Rooting intensity of M.7EMLA was ranked lower for the Marlette soil than the Canfield soil. This suggests adaptation of MAC.9 to heavy soils with M.9EMLA performing better in the Marlette soil and M.7EMLA performing poorly in the Marlette soil with the other rootstock not affected by soil type as far as total number of roots.

Although rootstock affected number of roots $/ \mathrm{dm}^{2}$ and depth of rooting, the soil environment had more influence on the root distribution pattern by depth. Depth of rooting was restricted by the fragipan in the Canfield soil and most roots were in soil layers above $60 \mathrm{~cm}$ since highly compacted pans present a physical barrier that severely limit root penetration (Eavis and Payne, 1968; Greaten et al., 1968). Between $91 \%$ and $94 \%$ of the total roots $/ \mathrm{dm}^{2}$ were located in the $\mathrm{O}$ to $60 \mathrm{~cm}$ depths for trees in the Canfield soil. The high percent of roots closer to the soil surface in the Canfield soil likely was caused by soil restriction of rooting volume. Increases in percent of root in regions closer to the soil surface in soils that restrict rooting volume has been observed for several fruit crops (Cockroft and Wallbrink, 1966; Oskamp, 1932). There was no such restriction to root distribution in the Marlette soil and roots were distributed fairly evenly throughout the soil profile with a moderate decrease in roots $/ \mathrm{dm}^{2}$ with depth and, in some cases, no decrease until the lowest depth measured. Between 55\% and 68\% with an average of $60 \%$ of the total roots $/ \mathrm{dm}^{2}$ were found in the $\mathrm{O}$ to $60 \mathrm{~cm}$ depths for trees in the Marlette soil. Soil texture also may be involved since Rogers and Vyvyan(1934) found an increase in total weight of four Mailing apple rootstock root systems from a heavy clay to a light sand to a loam. Several authors have found a rootstock soil interaction for various tree crops with rootstock performing differently under the diverse soil types (Cockroft and Wallbrink, 1966; Greaten et al., 1968;Irizarry et al.,1981; Mikhail and E1-Zeftawi, 1978; Oskamp and Batjer, 1932; Rogers and Vyvyan, 1934). This confirms the observation of this study regarding MAC.9 and M.9EMLA adaptation to soil environment.

Regression analysis showed strong positive correlations between number of roots (total roots and all size categories) vs. TCA, tree height and canopy spread $(P<0.001)$ but not yield in 1989 nor cumulative 10-year yield for the Marlette soil. The highest $R^{2} S$ were obtained when large roots were used for the regression analysis for trees in the Marlette soil. The models for total roots and 

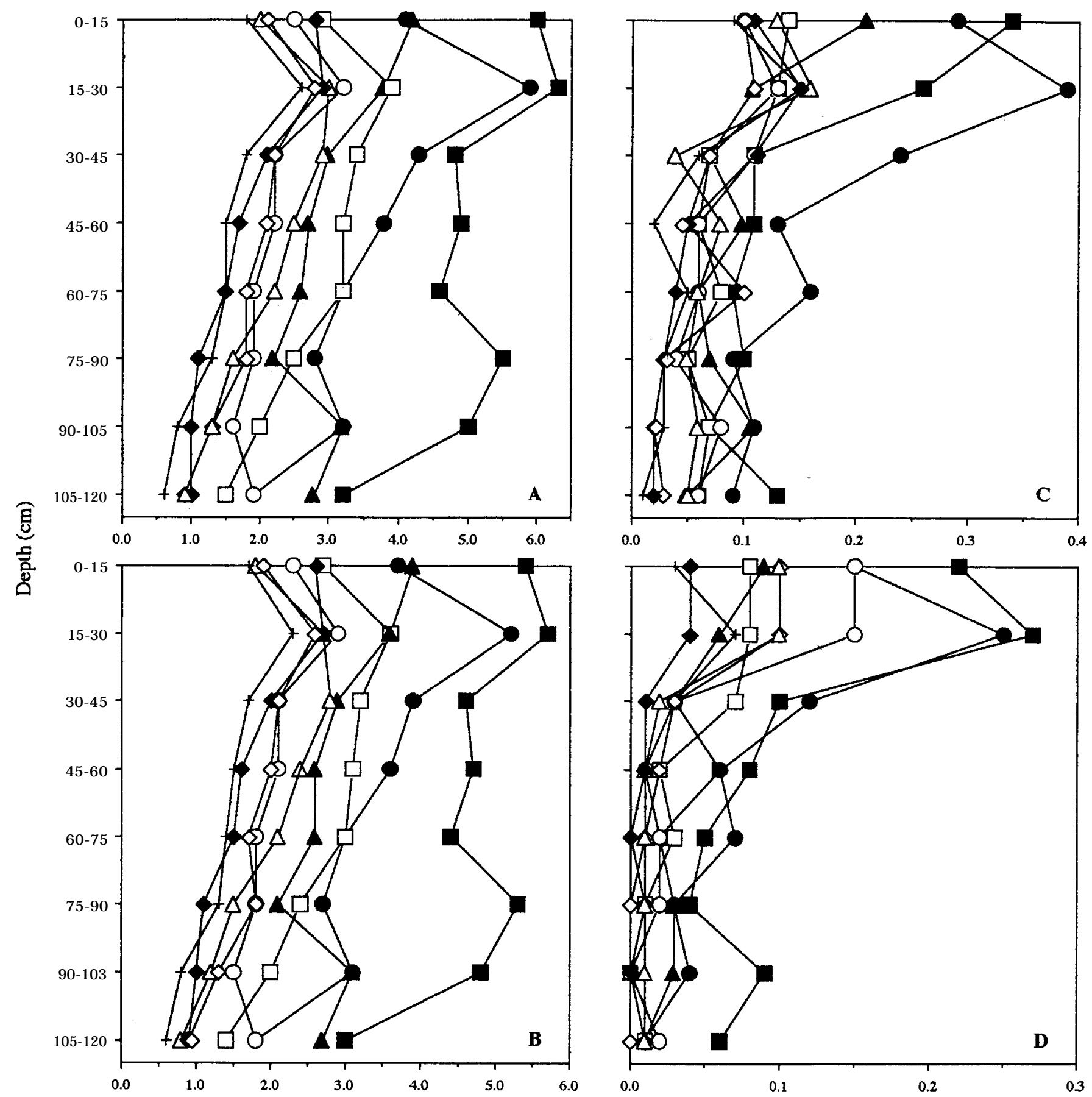

Roots / dm ${ }^{2}$

Fig. 1. Number of roots $/ \mathrm{dm}^{2}$ for each depth for the Marlette soil for total (A), small (B), medium (C), and large (D). LSD at $P=0.05$ for comparison of rootstock within depth for $\mathbf{A}$ and $\mathbf{B}$ (LSD identical for $\mathbf{A}$ and $\mathbf{B}$ ), C, D, respectively: 0.90,0.09,0.07 for O to $15 \mathrm{~cm}$ and 15 to $30 \mathrm{~cm} ; 0.80,0.07,0.04$ for 30 to $45 \mathrm{~cm}$; $0.80,0.06,0.03$ for 45 to $60 \mathrm{~cm} ; 0.70,0.06,0.03$ for 60 to $75 \mathrm{~cm} ; 0.70,0,04,0.03$ for 75 to $90 \mathrm{~cm}, 0.90,0.05,0.03$ for 90 to $105 \mathrm{~cm} ; 0.70,0.06,0.02$ for 105 to $120 \mathrm{~cm}$. LSD at P=0.05 for comparison of depth within rootstock: 1.3 for MAC.24( $\boldsymbol{\square})$; 0.9 for OAR $1(\bullet)$; 1.0 for M.26EMLA ( $\boldsymbol{\Delta}$ ); 0.7 for M.9EMLA ( $\square$ ); 0.6 for M.7EMLA ( $\bigcirc$ ) and 0.3 ( $\boldsymbol{\Delta}$ ); 0.5 for M.9 (light diamond) and MAC.9 (dark diamond); and 0.4 for M.27EMLA (+). 

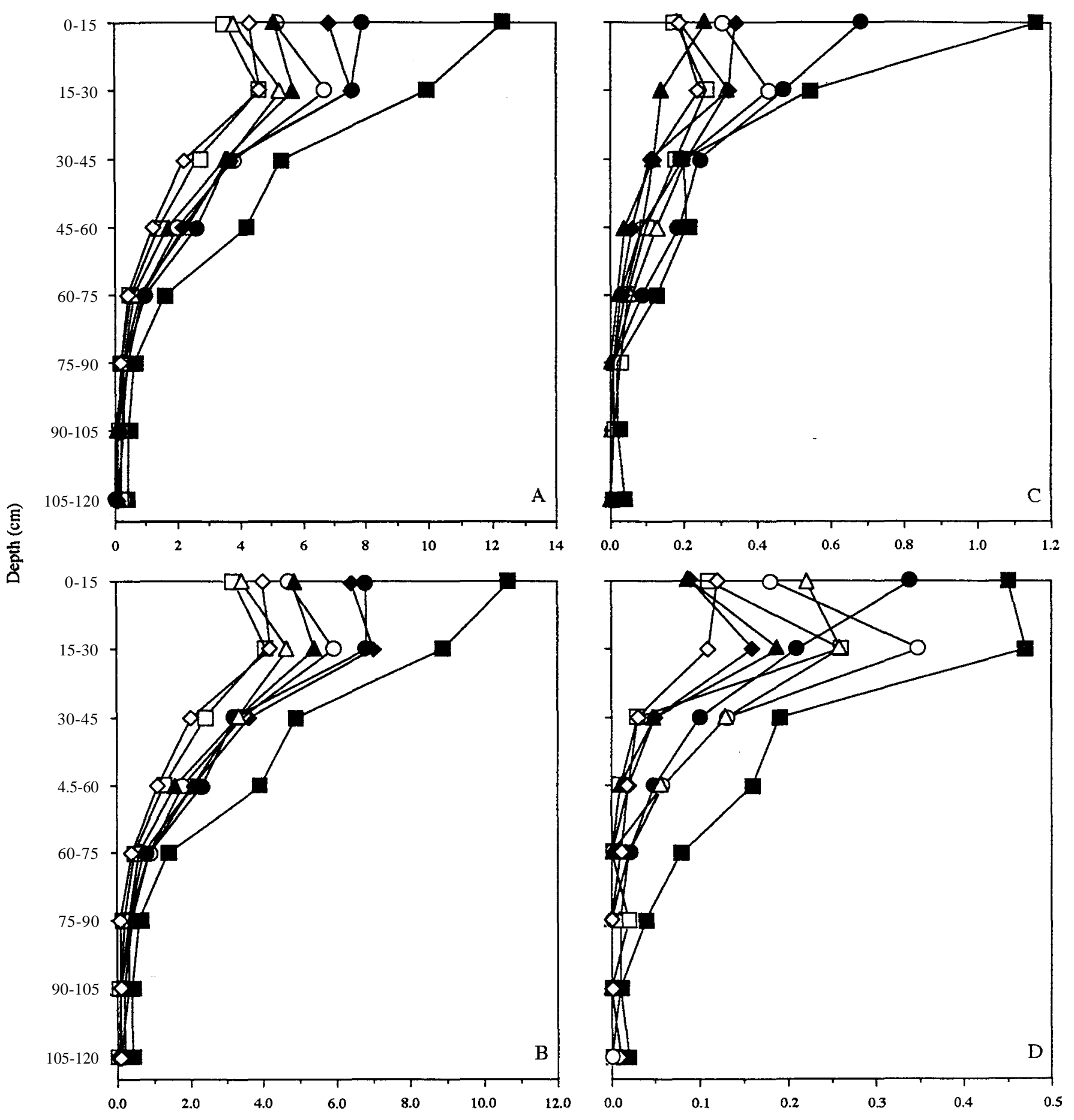

$\operatorname{Roots} / \mathbf{d m}^{2}$

Fig. 2. Number of roots $/ \mathrm{dm}^{2}$ for each depth for the Canfield soil for total (A), small (B), medium (C), and large (D). LSD at $P=0.05$ for comparison of rootstock within depth for total (A), small (B), medium (C) and large (D) roots $/ \mathrm{dm}^{2}$ respectively: 2.40,2.20,0.22,0.12 for O to $15 \mathrm{~cm} ; 1.50,1.40, .015,0.12$ for 15 to $30 \mathrm{~cm}$; $0.90,0.80,0.10,0.07$ for 30 to $45 \mathrm{~cm} ; 0,70,0.70,0.08,0.05$ for 45 to $60 \mathrm{~cm}$; $0.40,0.40,0.06,0.03$ for 60 to $75 \mathrm{~cm} ; 0.10,0.20,0.02,0.02$ for 75 to $90 \mathrm{~cm}$; $0.10,0.10,0.02,0.01$ for 90 to $105 \mathrm{~cm}$; $0.10,0.10,0.02,0.02$ for 105 to $120 \mathrm{~cm}$. LSD at $\boldsymbol{P}=0.05$ for comparison of depth within rootstock 1.3 for MAC.24 ( $\boldsymbol{\square}$ ); 0.9 for OAR 1 ( $\bullet$ ); 1.0 for M.26EMLA ( $\boldsymbol{\Delta}$ ); 0.7 for M.9EMLA ( $\square$ ); 0.6 for M.7EMLA $(O)$ and $0.3(\Delta) ; 0.5$ for M.9 (light diamond ) and MAC.9 (dark diamond). 
Table 3. Relationship between total root number and root size category having the highest coefficient of determination vs. scion vigor and yield for all rootstock.

\begin{tabular}{|c|c|c|c|c|}
\hline y Parameter & x Parameter & Equation & $R^{2}$ & $P$ value \\
\hline & & \multicolumn{3}{|c|}{ Marlette soil } \\
\hline \multirow[t]{2}{*}{ Trunk cross-sectional area (cm') } & Total roots & $13.504+0.039 x$ & 0.39 & 0.001 \\
\hline & Large roots & $18.430+1.880 \mathrm{x}$ & 0.61 & 0.001 \\
\hline \multirow[t]{2}{*}{ Tree height (m) } & Total roots & $y=199.932+0.076 x$ & 0.29 & 0.001 \\
\hline & Large roots & $2.009+0.036 \mathrm{x}$ & 0.45 & 0.001 \\
\hline \multirow[t]{3}{*}{ Canopy spread (m) } & Total roots & $y=195.213+0.064 x$ & 0.24 & 0.001 \\
\hline & Large roots & $\mathrm{y}=2.043+0.030 \mathrm{x}$ & 0.37 & 0.001 \\
\hline & & Canfield & & \\
\hline \multirow[t]{2}{*}{ Trunk cross-sectional area (cm') } & Total roots & $y=26.076+0.617 x$ & 0.36 & 0.001 \\
\hline & Medium and large roots & $y=-43.698+7.789 x$ & 0.65 & 0.001 \\
\hline \multirow[t]{2}{*}{ Tree height $(\mathrm{m})$} & Total roots & $\mathrm{y}=1.949+0.001 \mathrm{x}$ & 0.28 & 0.001 \\
\hline & Medium and large roots & $\mathrm{y}=1.752+0.014 \mathrm{x}$ & 0.58 & 0.001 \\
\hline \multirow[t]{2}{*}{ Canopy spread (m) } & Total roots & $y=2.702+0.001 x$ & 0.08 & 0.090 \\
\hline & Medium and large roots & $y=2.251+0.011 x$ & 0.42 & 0.001 \\
\hline \multirow[t]{2}{*}{1989 Yield (kg) } & Total roots & $\mathrm{y}=14.199+0.036 \mathrm{x}$ & 0.22 & 0.005 \\
\hline & Medium and large roots & $y=4.173+0.516 x$ & 0.54 & 0.001 \\
\hline \multirow[t]{2}{*}{ 10-Year cumulative yield (kg) } & Total roots & $\mathrm{y}=98.498+0.090 \mathrm{x}$ & 0.23 & 0.005 \\
\hline & Medium and large roots & $y=80.809+1.209 x$ & 0.48 & 0.001 \\
\hline
\end{tabular}

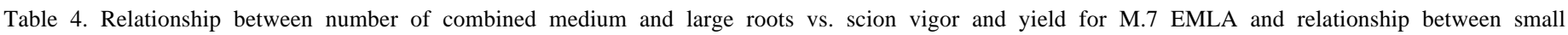
roots vs. combined medium and large roots for all rootstock.

\begin{tabular}{|c|c|c|c|c|}
\hline y Parameter & $\mathrm{x}$ Parameter & Equation & $R^{2}$ & $P$ value \\
\hline & & \multicolumn{3}{|c|}{ Marlette soil } \\
\hline Small roots & Medium and large roots & $y=212.700+13.760 x$ & 0.73 & 0.001 \\
\hline M.7EMLA small roots & M.7EMLA medium and large roots & $\mathrm{y}=433.890+7.430 \mathrm{x}$ & 0.94 & 0.010 \\
\hline & & \multicolumn{3}{|c|}{ Canfield soil } \\
\hline M.7EMLA TCA $\left(\mathrm{cm}^{2}\right)$ & Medium and large roots & $y=166.620-0.691 x$ & 0.95 & 0.010 \\
\hline M.7EMLA tree height (m) & Medium and large roots & $8.033-0.043 x$ & 0.98 & 0.010 \\
\hline M.7EMLA 1989 Yield (kg) & Medium and large roots & $y=226.110-1.461 x$ & 0.97 & 0.010 \\
\hline \multicolumn{5}{|l|}{ M.7EMLA } \\
\hline 10-Year cumulative yield (kg) & Medium and large roots & $y=486.280-2.486 x$ & 0.99 & 0.010 \\
\hline Small roots & Medium and large roots & $y=440.180+5.945 x$ & 0.49 & 0.001 \\
\hline M.7EMLA small roots & M.7EMLA medium and large roots & $y=2593.900-17.173 x$ & 0.73 & 0.050 \\
\hline
\end{tabular}

large roots vs. TCA, tree height and canopy spread for the Marlette soil are shown in Table 3. All linear regression models between number of roots (total roots and all size categories) vs. TCA, tree height, canopy spread, 1989 yield and 10-year cumulative yield for trees in the Canfield soil were highly significant $(P<0.01)$ except for total and small roots vs. canopy spread. Maximum $R^{2}$ values were found for medium or large roots vs. the vigor and yield parameters for trees in the Canfield soil. These two categories were analyzed together as combined medium and large roots and were compared with the vigor and yield components listed above. The $R^{2} \mathrm{~S}$ for combined medium and large roots were higher than for medium or large roots alone for trees in the Canfield soil. Regression models for total roots and combined medium and large roots vs. vigor and yield parameters for the Canfield soil are shown in Table 3.

Scion vigor and the intensity and extensiveness of the root system has been shown to be positively correlated for many apple rootstock (Atkinson, 1980; Avery, 1970; Coker, 1958; Rogers and Vyvyan, 1934). The positive relationship found for TCA, tree height, and canopy spread of the scion vs. number of roots counted demonstrates that tree vigor can be used to give a rough estimate of root system size of these rootstock with the exception of
M.7EMLA for these soils. The higher correlation coefficients with medium and large roots could reflect their longevity, which may indicate a cumulative measure of root system size in the same way that TCA, tree height, and canopy spread reflect a cumulative measure of the above ground portion of the tree, whereas, a substantial proportion of the small roots may die (Smucker, 1984).

Linear regression analysis showed a positive correlation between 1989 yield and cumulative yield vs. the number of total roots counted for the Canfield soil. The $R^{2}$ S were much higher for 1989 yield and cumulative yield vs. combined medium and large roots in the Canfield soil than for total roots (Table 3). The higher correlation between medium and large roots with yield parameters in the Canfield soil may be related to over-winter carbohydrate storage in these roots as larger roots are more likely to over winter and store larger amounts of carbohydrates than small roots (Kramer and Kozlowski, 1979; Abed and Webster, 1991). Also, the contribution of older roots to water and nutrient uptake during the summer and early fall can be substantial when water demand is highest, when new root growth lowest and there is a high fruit growth rate (Atkinson, 1980; Rem, 1987). No significant correlation was found for yield parameters and root numbers in the Marlette soil. This maybe due to a smaller percentage of medium 
and large roots compared to small roots in the Marlette soil than the Canfield soil (Fernandez et al., 1991).

It was noticed that M.7EMLA displayed a negative slope on most of the regression lines where all rootstock were included. Therefore, individual rootstock were subjected to regression analysis for total roots and all size categories vs. growth and yield parameters. All rootstock were found to have a positive or nonsignificant relationship individually (data not shown) except M.7EMLA. A strong negative relationship was found for M.7EMLA between TCA, tree height, 1989 yield, and 10 year cumulative yield compared with root data for the Canfield soil. Maximum $R^{2}$ was found for growth and yield parameters vs. combined number of medium and large roots (Table 4). Negatives slopes also were detected for tree height, canopy spread and 1989 yield vs. combined medium and large roots for the Marlette soil, although the relationships were not significant (data not shown).

As a result of these findings, the relationship between the number of small roots to number of combined medium and large roots was examined for all rootstock combined and individual rootstock. For all rootstock combined. there was a significant positive relationship between the number of small roots vs. combined medium and large roots. The same results were obtained for regression analysis of individual rootstock except M.7EMLA, which displayed a strong negative correlation in the Canfield soil but a positive correlation for the Marlette soil (Table 4).

The highly significant negative correlations found in the Canfield soil for M.7EMLA between combined medium and large roots vs. TCA, tree height, 1989 yield, cumulative yield and small root number may indicate a strong competition for carbohydrates between the medium and large roots and the rest of the plant. The positive relationship between combined medium and large roots vs. small roots over all rootstock demonstrates a balanced root system. The strong negative correlation between combined medium and large roots vs. small roots for M.7EMLA in the Canfield soil indicates an unbalanced root system under these soil conditions.

The negative relationship between combined medium and large roots vs. small roots observed for the Canfield soil may explain observations of poor anchorage, leaning, and an asymmetric root system of M.7EMLA under certain situations (Ferree and Carlson, 1987). Medium and large roots accounted for only $8 \%$ of the root system for M.7EMLA in the Canfield soil (Fernandez et al., 1991) but with an increase from $\approx 75$ to 105 medium and large roots, there was a decrease from approximately 1150 to 650 small roots, i.e., for each increase of one medium or large root there was a decrease of 17 small roots. This large reduction in the number of small roots with a slight increase in medium and large roots could explain poor anchorage of M.7EMLA under circumstances where more larger roots are produced.

The greatest effect on the total number of roots $/ \mathrm{dm}^{2}$ over all depths was due to rootstock. Rootstock were similar at both soil types with respect to the total number of roots $/ \mathrm{dm}^{2}$ and small roots/ $\mathrm{d} \mathrm{m}^{2}$ over all depths with only three rootstock exhibiting differences due to soil type. MAC.9 formed more roots $/ \mathrm{dm}^{2}$ than expected when compared to tree vigor in the Canfield soil and had a higher relative ranking than in the Marlette soil. M.9EMLA formed more roots $/ \mathrm{dm}^{2}$ than expected when compared to tree vigor in the Marlette soil and had a higher relative ranking than in the Canfield soil. M.7EMLA formed fewer roots $/ \mathrm{dm}^{2}$ than expected when compared to tree vigor in the Marlette soil and a lower relative ranking than in the Canfield soil.

The overall size of the root system appeared to be controlled by the genotype while the root distribution pattern was affected by the soil environment. An even distribution of roots or moderate decrease in the number of roots $/ \mathrm{dm}^{2}$ with greater depths was observed for trees in the lighter fine sandy loam (Marlette) but a restriction of most roots above the fragipan was seen for trees in the heavier silt loam (Canfield). The soil volume available to the root systems of trees in this study was greatly reduced in the Canfield soil by the fragipan. Additionally, up to twice as many roots $/ \mathrm{dm}^{2}$ were present in the zone above the fragipan in the Canfield soil than at the same depths for the Marlette soil. Plants with large root systems restricted to small soil volumes, such as was found for MAC.24 in the Canfield soil, are likely to respond differently to environmental conditions or imposed treatments compared to the same plants with unrestricted soil volumes. The combination of a high root density in a shallow soil volume could alter plant response to soil stresses such as flooding or drought stress by more rapid depletion of soil water and gases. Positive relationships were found for vigor and yield parameters compared with number of roots for all rootstock except M.7EMLA where a possible competitive effect was found between vigor, yield, and small roots vs. combined medium and large roots. Based on relative ranking of rooting intensity for the two soil types M.9EMLA, MAC.9, and M.7EMLA were affected by soil type. It is important to consider the ability of plants to alter root distribution patterns without apparent reductions in the overall size of the root system in response to changes in the soil environment as found in this study when selecting rootstock and management systems both for orchardists and researchers.

\section{Literature Cited}

Abed, S.A. and A.D. Webster. 1991. Carbohydrates and their effects on growth and establishment of Tilia and Betula: I. Seasonal changes in soluble and insoluble carbohydrates. J. Hort. Sci. 66:235-246.

Anonymous. 1979. Soil survey of Ingham County, Michigan. USDA Soil Conserv. Service, Natl. Coop. Soil Survey. Washington D.C.

Anonymous. 1981. Soil survey of Wayne County, Ohio. USDA Soil Conserv. Service, Natl. Coop. Soil Survey. Washington D.C.

Atkinson, D. 1980. The distribution and effectiveness of the roots of tree crops. Hort. Rev. 2:424-490.

Avery, D.J. 1970. Effects of fruiting on the growth of apple trees on four rootstock varieties. New Phytol. 69: 19-30.

Cockroft, B. and J.C. Wallbrink. 1966. Root distribution of orchard trees. Austral. J. Agri. Res. 17:49-54.

Coker, E.G. 1958. Root studies. XII. Root systems of apple on Mailing rootstock on five soil series. J. Hort. Sci. 33:7 1-79.

Eavis, B.W. and D. Payne. 1968. Soil physical conditions and root growth, p. 256-269. In: W.J. Whittington (cd.). Root growth. Butterworths, London.

Ferree, D.C. and R.F. Carlson. 1987. Apple rootstock, Rootstock for fruit crops. R.C. Rom and R.F. Carlson (eds.). Wiley, New York. p. 107143.

Ferree, D.C and R.L. Perry. 1988. Rootstock evaluation through the NC140 project. HortScience 23: 102-104.

Fernandez, R. T., R.L. Perry, and D.C. Ferree. 1991. Rooting characteristics of apple rootstock at two NC-140 trial locations. Fruit Var. J. 45:264-268.

Greaten, E. L., K.P. Barley, and D.A. Farrell. 1968. The mechanics of root growth in soil with particular reference to the implications for root distribution, p. 256-269. In: W.J. Whittington (cd.). Root growth. Butterworths, London.

Irizarry, H., J. Vicente-Chandler, and S. Silva. 1981. Root distribution of plantains growing on five soil types. J. Agri. Univ. of Puerto Rico. 65:29-34.

Kramer, P.J. and T.T. Kozlowski. 1979. Physiology of woody plants. Academic Press, New York. p. 258-281.

Layne, R. E. C., C.S. Tan, and R.L. Perry. 1986. Characterization of peach roots in fox sand as influenced by sprinkler irrigation and tree density. 
J. Amer. Soc. Hort. Sci. 111:670-677.

Mikhail, E.H. and B.M. E1-Zeftawi. 1978. Effect of soil types and rootstock on root distribution and leaf composition of citrus trees. Proc. Intl. Soc. Citricult. 214-216.

NC- 140.1991. Performance of' Starkspur Supreme Delicious' apple on 9 rootstock at 27 sites over 10 years. Fruit Var. J. 45:200-208.

Oskamp, J. 1932. The rooting habit of deciduous fruits on different soils. Proc. Amer. Soc. Hort. Sci. 29:213-219.

Oskamp, J. and L.P. Batjer. 1932. Soils in relation to fruit growing in New York. II. Size, production and rooting habit of apple trees on different soil types in the Helton and Morton areas, Monroe County. Cornell Univ. Agr. Expt. Sta. Bul. 550:145.

Perry, R. L., S.D. Lyda, and H.H. Bowen. 1983. Root distribution of four Vitis cultivars. Plant and Soil 71:63-74.
Rogers, W.S. and M.C. Vyvyan. 1934. Root studies V. Rootstock and soil effect on apple trees. J. Pomol. Hort. Sci. 43:110-150.

Rem, R.C. 1987. Roots. Rootstock for fruit crops, p. 5-28. R.C. Rom and R.F. Carlson (eds.). Wiley, New York.

Smucker, A.J.M. 1984. Carbon utilization and losses by plant mot systems. In: Roots, nutrient and water influx and plant growth, p. 2746. S.A. Barber and D.R. Bouldin (d.). Soil Sci. Soc. Amer., Madison, Wis.

Taylor, H.M. and H.R. Gardner. 1963. Penetration of cotton seedling taproots as influenced by bulk density, moisture content, and strength of soil. Soil Sci. 96: 153-156.

Warmund, M. R., D.C. Ferree, P. Domoto, J.A. Barden, C.A. Mullins, and R.L. Granger. 1991. Blackheart injury in 'Starkspur Supreme Delicious' on nine rootstock in the 1980-1981 NC-140 cooperative planting. Fruit Var. J. 45:219-223. 